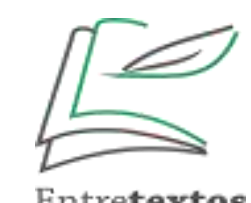

Entretextos 21(3): especial, 2021

ISSN (digital): 2764-0809

ISSN (impresso): 1519-5392

DOI: $10.5433 / 1519-5392.2021 v 21 n 3 E s p . p 78$

\title{
Ensino de português para estrangeiros em instituições tecnológicas do Rio de Janeiro: o caso do CEFET/RJ
}

\author{
Teaching Portuguese to foreigners in technological institutions in \\ Rio de Janeiro: the case of CEFET/RJ
}

\section{Enseñanza de portugués para extranjeros en instituciones tecnológicas de Río de Janeiro: el caso del Cefet/Rj}

\author{
Antonio Ferreira da Silva Júnior ${ }^{1}$ \\ https://orcid.org/0000-0002-2161-4517 \\ Beatriz Puga dos Santos ${ }^{2}$ \\ https://orcid.org/0000-0002-5422-0610
}

\begin{abstract}
RESUMO: Este artigo tem por objetivo demonstrar a importância da inserção da área de português como língua estrangeira (PLE) no contexto da internacionalização de instituições tecnológicas federais do Rio de Janeiro e como esse idioma pode se configurar nas políticas institucionais locais. Para exemplificar uma dessas ações, optou-se por relatar a experiência do CEFET/RJ em um projeto de extensão de ensino de PLE. A metodologia adotada para o estudo consistiu na pesquisa bibliográfica sobre textos relacionados ao tema da internacionalização (KNIGHT, 2004, 2015), das políticas linguísticas (BIZON, 2013) e da área de ensino de PLE (DINIZ, 2008). Também se analisou sites das instituições elencadas e todos os conteúdos referentes às políticas de internacionalização relacionadas à área de PLE. Após coleta de dados e do relato da experiência no CEFET/RJ, concluiu-se que o foco das instituições ainda não está nas políticas de implementação de ações de PLE e falta conhecimento sobre a internacionalização e seus impactos, o que ocasiona carência de convênios e presença de intercambistas em mobilidade. A pesquisa documenta os posicionamentos das instituições diante dos temas propostos e também apresenta a relevância da internacionalização e da institucionalização da área de PLE no futuro das instituições tecnológicas de ensino superior.
\end{abstract}

PALAVRAS-CHAVE: Português para Estrangeiros. Internacionalização. Instituições tecnológicas.

\footnotetext{
${ }^{1}$ Doutor em Letras Neolatinas pela Universidade Federal do Rio de Janeiro (UFRJ) e Professor de Língua Espanhola da UFRJ, atuando no Colégio de Aplicação e no Programa de Pós-Graduação em Letras Neolatinas. E-mail: afjrespanhol@gmail.com

2 Graduada em Línguas Estrangeiras Aplicadas às Negociações Internacionais no Centro Federal de Educação Tecnológica Celso Suckow da Fonseca (CEFET/RJ). E-mail: beapuga1234@gmail.com
} 
ABSTRACT: This article aims to demonstrate the importance of inserting Portuguese for foreigners (PLE) area in the context of internationalization of federal technological institutions in Rio de Janeiro and how this language can be configured in local institutional policies. To exemplify one of these actions, we chose to report the experience of CEFET/RJ in a PLE teaching extension project. The methodology adopted for study consisted of bibliographical research on texts related to internationalization themes (KNIGHT, 2004, 2015), language policies (BIZON, 2013) and the teaching area of PLE (DINIZ, 2008). We also analyzed the websites of listed institutions and all the contents related to internationalization policies and the PLE area. After collecting data and reporting the experience at CEFET/RJ, it was concluded that the focus of institutions is not yet on policies for implementing PLE actions, there is a lack of knowledge about internationalization and its impacts, which causes a scarcity of covenant and presence of exchange students in mobility. The research documents the institutions' positions on the proposed themes and also presents the relevance of internationalization and institutionalization of the PLE area in the future of technological institutions of higher education.

KEYWORDS: Portuguese for Foreigners. Internationalization. Technological institutions.

RESUMEN: Este texto tiene como objetivo demostrar la importancia del área de portugués como lengua extranjera (PLE) en el contexto de la internacionalización de instituciones tecnológicas federales de Río de Janeiro y cómo ese idioma puede configurarse en las políticas institucionales. Para ejemplificar una de esas acciones, se eligió la experiencia del CEFET/RJ en un proyecto de extensión de enseñanza de PLE. La metodología se basó en la investigación bibliográfica a respecto de textos relacionados a la internacionalización (KNIGHT, 2004, 2015), las políticas lingüísticas (BIZON, 2013) y el área de la enseñanza de PLE (DINIZ, 2008). También se hizo un análisis de sitios de las instituciones y los contenidos involucrados a las políticas de internacionalización. Tras la colecta de datos y relatos de experiencia en CEFET/RJ, se concluyó que el foco de las instituciones todavía no está en las políticas de inserción de PLE y falta conocimiento sobre la internacionalización y sus impactos, lo que genera carencia de convenios y presencia de intercambistas en movilidad. La investigación documenta los posicionamientos de las instituciones delante de los temas propuestos y destaca la relevancia de la internacionalización y la institucionalización del área de PLE en el futuro de las instituciones tecnológicas de enseñanza superior.

PALABRAS CLAVE: Portugués para Extranjeros. Internacionalización. Instituciones tecnológicas.

\section{Introdução}

O presente artigo aponta e analisa as ações que envolvem o ensino de português como língua estrangeira (PLE), desenvolvidas por instituições tecnológicas de ensino localizadas no Rio de Janeiro. Assim, aborda o processo de internacionalização dessas instituições e observa toda e qualquer política adotada para o ensino da língua portuguesa direcionado aos alunos em mobilidade internacional. Para isso, o texto busca entender como cada instituição tecnológica de ensino pensa suas ações de PLE e quais as iniciativas tomadas, até o momento, para a difusão da língua em conjunto com o auxílio à adaptação dos estudantes intercambistas. O estudo também retrata a realidade de um projeto de extensão desenvolvido no Centro Federal de Educação Tecnológica Celso Suckow da 
Fonseca (CEFET/RJ) como política institucional e de ensino para acolhimento de estudantes estrangeiros.

Com a intenção de formular um estudo em que o foco são as políticas de ensino de PLE em instituições previamente selecionadas, espera-se contribuir para a amplificação dessa área de estudos. Por esse motivo, são expostas algumas noções sobre o processo de internacionalização, já que é dentro desse que se encontram quaisquer atividades e projetos considerados parte de um cronograma internacional. Além disso, baseando-se no elemento norteador da pesquisa, também se apresentam definições acerca do que são as "políticas de línguas" e uma síntese sobre os marcos do ensino de PLE no Brasil.

Para este artigo, tomou-se como objeto de análise três instituições tecnológicas: CEFET/RJ, o Colégio Pedro II (CPII) e o Instituto Federal Fluminense (IFF), as quais enquadram-se na Lei no 11.892, de 29 de dezembro de 2008 (BRASIL, 2008), ou seja, são instituições que possuem três níveis educacionais (superior, básica e profissional), são pluricurriculares e multicampi e especializadas em ofertar educação profissional e tecnológica4.

$O$ estudo concentra informações que dizem respeito à internacionalização e políticas de ensino de PLE a partir de informações disponibilizadas nos sites eletrônicos institucionais dessas instituições e que estão disponíveis para toda a comunidade científica. As respectivas informações coletadas dão margem para análises comparativas e muitos desdobramentos. Dessa forma, é possível apontar também o que existe em comum entre as instituições e como elas elaboram políticas mais diversificadas que acompanhem o seu respectivo nível de internacionalização.

$O$ trabalho demonstra os tipos de políticas de ensino de português desenvolvidos por cada instituição, e, mais ainda, observar se essas políticas atendem de alguma forma à comunidade internacional interna que vem se formando dentro dos respectivos institutos averiguados. Conforme mencionado no início da Introdução, explora-se somente o exemplo de um projeto de extensão do CEFET/RJ por ser a instituição de pesquisa dos autores deste artigo e por ser o instituto que mais tempo dedica ao tema da internacionalização e ensino de PLE.

\footnotetext{
3 Para esta pesquisa, optou-se por excluir o Instituto Federal do Rio de Janeiro (IFRJ) da análise por não ter sido facilitado o acesso a muitas informações sobre a área internacional e de PLE em seu site institucional.

${ }^{4}$ De acordo com o Art. $2^{\circ}$ da Lei no 11.892, de 29 de dezembro de 2008 (Vide Decreto no 7.022, de 2009).
} 
A seguir, organiza-se o texto apresentando a motivação da pesquisa realizada e, em seguida, uma síntese teórica dos debates sobre internacionalização do ensino superior e sua relação com as políticas de PLE. Após isso, apresenta-se um mapeamento das ações desenvolvidas pelas instituições elencadas para o estudo e destaca-se um projeto de extensão como política institucional. Por último, retomam-se aspectos centrais do estudo e uma síntese das diferentes realidades institucionais.

\section{Como surge a ideia da pesquisa em questão?}

A pesquisa em questão surge de um projeto de extensão e investigação desenvolvido no curso de Bacharelado em Línguas Estrangeiras Aplicadas às Negociações Internacionais (LEANI), ofertado pelo CEFET/RJ. O curso, desde seu projeto pedagógico, está profundamente vinculado ao anseio de internacionalização institucional, além de contribuir para a formação de um profissional internacionalista que seja capaz de dominar muitas línguas estrangeiras e que seja dotado de um conhecimento de estudos da Linguagem e de políticas linguísticas. Portanto, o Bacharelado LEANI é uma consequência do avanço das pesquisas da área de línguas estrangeiras e do crescente processo de internacionalização da própria instituição (NORTE; SILVA JÚNIOR, 2018).

Apesar de o curso em tela não ser de Licenciatura, o projeto foi idealizado como forma de colocar em prática saberes das áreas de Linguística Aplicada, de Identidades Culturais e da Comunicação Intercultural no cotidiano formativo dos estudantes do Bacharelado. Dessa forma, os bolsistas do projeto em questão podem mobilizar conhecimentos de distintas naturezas no desenho de ações que pudessem colaborar para o acolhimento de estudantes intercambistas da própria instituição.

O projeto de extensão "Oficinas de ensino de Português para Estrangeiros", que foi detalhado neste artigo, tinha por objetivo atender à comunidade interna do CEFET/RJ, oferecendo encontros para a aprendizagem da língua e cultura do português, além de oferecer um espaço para discussões e reflexões acerca do cotidiano dos intercambistas na cidade do Rio de Janeiro e de como suas experiências estavam transcorrendo.

Para este artigo, são apresentados somente dados mapeados mediante pesquisa bibliográfica realizada no início do projeto sobre o cenário da internacionalização das instituições tecnológicas e a área de PLE, além de indicar o projeto do CEFET/RJ como uma ação que possa contribuir para repensar a internacionalização institucional e o 
crescimento das pesquisas em PLE.

\section{A Internacionalização do Ensino Superior}

A maior parte dos artigos e documentos que tratam sobre ensino superior brasileiro e internacionalização salientam que a produção científica escassa sobre o tema dificulta a formação de um conceito comum e absoluto. Altbach e Knight (2007) enxergam a internacionalização como o conjunto de políticas e práticas que são empreendidas por sistemas acadêmicos, instituições e indivíduos para lidar com o ambiente acadêmico global. Além disso, os autores estabelecem a diferenciação entre os propósitos econômicos adotados pela globalização e as práticas do âmbito educacional.

A globalização possui ligação direta com a internacionalização, pois se considera a segunda como uma consequência da primeira. Morosini (2006) aponta que foi com o fenômeno da globalização que a internacionalização da educação superior passou a se fortificar mundialmente. A autora ainda retoma Knight (2004) para reforçar a relação entre os dois fenômenos e como cada um exerce influência sobre o outro.

Senhoras (2006) considera a cooperação internacional como um sistema de comunicação que permite a passagem de fluxos de conhecimento e cultura que influenciam no desenvolvimento dos parceiros envolvidos, possibilitando o progresso de ambos nos quesitos comercial, industrial e científico. Por isso, com relação a esse sistema de comunicação, Knight (2015) estabelece a separação entre os investimentos na internacionalização da educação, a nível macro (países) e a nível meso (instituição de educação). A partir dessa separação em níveis, convencionou-se que existem intenções e objetivos em cada nível de cooperação, e que esses podem se converter em promoção de alianças estratégicas, desenvolvimento sociocultural, notabilidade internacional, entre outros (LIMA; MARANHÃO, 2009, p. 589).

Teichler (2004) acredita que todas as universidades devem ser internacionais e que o tema da internacionalização constitui a administração institucional e permeia as tomadas de decisão das instituições. $\mathrm{O}$ autor reflete criticamente sobre o aprendizado e a pesquisa em outros países ao reconhecer que o intercâmbio internacional é uma das formas mais eficientes de se adquirir conhecimento. E essa análise crítica aponta problemas, como as distintas políticas de créditos em universidades de diferentes países. Mas, mesmo assim, ele considera a mobilidade como uma das principais formas de internacionalização. 
Defende-se, neste artigo, a perspectiva de Knight (2004) ao considerar a internacionalização como processo, e sua íntima relação com a crescente globalização. Também é adotada a conceituação de internacionalização universitária da autora, que a define como "o processo que integra uma dimensão global, intercultural e internacional nos objetivos, funções e oferta de educação pós-secundária" (KNIGHT, 2004, p. 11).

\section{As políticas linguísticas e o ensino de português língua estrangeira}

Com o desenvolvimento econômico e a entrada do Brasil para o Mercado Comum do Sul (Mercosul), o interesse pelo ensino qualificado da língua portuguesa se impulsionou, não só em meio aos países da América Latina, como em outros. Mas, até se chegar a esse momento, é preciso entender o que tem sido feito com relação ao ensino de PLE.

Os estudos de Almeida Filho (2017) são fundamentais para o entendimento da história do PLE no Brasil. O pesquisador apresenta alguns marcos simbólicos dessa trajetória, entre eles, destaca a criação em 1940 de Centros de Estudos Brasileiros, sendo o Instituto de Cultura Uruguaio-Brasileiro como o primeiro a ser instalado. Também recupera a publicação em 1957 do livro didático O ensino de português para brasileiros, de Mercedes Marchandt, em Porto Alegre, em que a autora relata sua experiência com o ensino de PLE em uma universidade no Rio Grande do Sul. Outra produção didática relevante é a coletânea Português do Brasil para falantes de espanhol, publicada em 1978, de autoria de Francisco Gomes de Matos e Sônia Biazioli, ambos atuantes no Centro de Linguística Aplicada Yázigi em São Paulo (ALMEIDA FILHO, 2017).

Outro fato marcante para o crescimento científico da área de PLE no Brasil ocorreu em 1993 com a criação pelo Ministério da Educação do Exame Nacional de Proficiência em Português (CELPE-Bras). Esse episódio foi fundamental para o planejamento de políticas de ensino e de formação de professores de PLE. Segundo Diniz (2008), foi em meados dos anos 1990 que se iniciou uma formação para professores em PLE de maneira formal, sendo assim reconhecida como uma nova área do conhecimento. Essa ação passou a contribuir diretamente para que o português pudesse vir a ser considerado uma língua transnacional. Além da formação de profissionais da área, houve um grande aumento de publicações acerca do assunto, e inclusive criou-se a associação científica voltada para esse tema, a Sociedade Internacional de Português Língua Estrangeira 
(SIPLE).

Conforme Moutinho e Almeida Filho (2017, p. 71), "os centros de pesquisas destinados especificamente a estudos de PLE e os programas de pós-graduação na área ainda são novos e exíguos". Desse modo, entende-se que a área de PLE vem sofrendo uma reestruturação e demandando maior difusão do conhecimento teórico e prático produzido por pesquisadores da área nos últimos anos.

O papel político assumido nos estudos realizados sobre PLE em contextos universitários no Brasil permitiu uma maior conscientização e valorização da área. Desse modo, uma conceituação fundamental para se entender o universo do PLE, e do ensino da língua de forma geral, é o campo das "políticas linguísticas". Diniz (2012) propõe repensar a política linguística, explicitando que não existe nenhuma maneira de uma língua não ser afetada pelo o que lhe é próprio: o político. Por isso, o autor sugere o termo "políticas de línguas", pois imediatamente se pensa em formas sociais que são significadas por e para os sujeitos históricos, de acordo com sua existência e experiência (DINIZ, 2012).

Além disso, a utilização do termo políticas de línguas dá a ideia não só de uma específica forma de política pública, já que a língua faz parte da vida social e histórica, e não se restringe apenas a decisões ou atos administrativos do estado (BIZON, 2013, p. 33). Por isso, deve-se ressaltar a importância de se reconhecer que as políticas de línguas também dizem respeito às práticas sociais do cotidiano. Portanto, não apenas as ações oficiais de uma determinada nação são consideradas como políticas linguísticas (BIZON, 2013). Ainda segundo Bizon (2013), a implementação de ações voltadas para o ensino de português como parte da própria política linguística é algo indispensável para a internacionalização das universidades e para a manutenção de convênios e intercâmbios estudantis.

Tratando-se da importância das políticas linguísticas aliadas ao processo de internacionalização das instituições, Bizon (2013) frisa que as políticas estabelecidas são as responsáveis para a efetivação sustentável do processo de internacionalização, cabendo a essas instituições estabelecer seus objetivos. Nesse âmbito, como forma de ilustrar uma realidade institucional, destaca-se o estudo de Chagas (2016) em sua atuação em uma universidade pública federal no interior de Minas Gerais. As situações retratadas pelo pesquisador possibilitam refletir sobre o quão importante é obter uma boa estrutura de recepção dos estudantes estrangeiros, e como a falta de uma política 
linguística de ensino de português em uma instituição não é uma justificativa para que não ocorra o ensino-aprendizagem da língua em questão.

Desde 2012, novos programas do Ministério da Educação como o Idiomas sem Fronteiras 5 tendem a contribuir para a instalação de políticas linguísticas e de mobilidade acadêmica das instituições de ensino, contribuindo para sua internacionalização. Com isso, ocorre a apertura para o trabalho com o PLE em algumas redes de ensino e o início do mapeamento de ações que têm por objetivo introduzir, recepcionar e acolher estudantes estrangeiros, aspectos que vão se abordados nas próximas seções deste texto por meio das instituições selecionadas.

\section{Desenho metodológico}

Os objetivos principais desenhados para o artigo foram identificar políticas linguísticas presentes nas instituições tecnológicas de ensino e como elas pensam o ensino de PLE, levando-se em consideração que essas informações influenciam a prática nesses centros educacionais.

Para reunir dados e informações mínimas para iniciar a investigação, foi pensado empregar algum recurso para acesso aos dados sobre a internacionalização desses institutos, o histórico de cooperação internacional e mobilidade. Também era preciso mapear iniciativas voltadas para o exercício do ensino de PLE, se atividades em torno dessa prática já eram implementadas ou se podiam ser encontradas facilmente. Para isso, optou-se por visitar e coletar informações das respectivas páginas institucionais no segundo semestre de 2018.

Após análise prévia dos sites oficiais das instituições, constatou-se que a maioria das informações sobre convênios institucionais, acordos internacionais e notícias sobre as atividades relacionadas à internacionalização e ensino de PLE são disponibilizadas para

\footnotetext{
${ }^{5}$ Cabe reforçar que, no segundo semestre de 2018, período de desenvolvimento da pesquisa relatada neste artigo, as instituições tecnológicas de ensino vinculadas à Rede Federal de Educação Profissional, Científica e Tecnológica ainda não estavam credenciadas a participar em sua totalidade do Programa Idiomas sem Fronteiras. As instituições tecnológicas nacionais foram convidadas somente por meio do Edital no 38/2018, de 10 de maio de 2018, para atuarem na composição de Núcleos de Línguas no âmbito do referido Programa. Antes de 2018, algumas instituições participavam de ações isoladas vinculadas ao Inglês sem Fronteiras, mas o Programa estava mais consolidado no contexto das Universidades federais e estaduais. Destaca-se que um dos objetivos do Programa Idiomas sem Fronteiras está em contribuir para a internacionalização do Ensino Superior brasileiro por meio do desenvolvimento de uma política linguística nacional. Nesse âmbito, tem-se a formação e capacitação de estrangeiros em língua estrangeira. Para ter acesso ao histórico do Programa, recomenda-se a leitura de Abreu-e-Lima, Sarmento e Moraes Filho (2016) sobre o desenvolvimento e abrangência do Idiomas sem Fronteiras.
} 
divulgação. A partir da análise dos dados encontrados, buscou-se propor um diálogo entre os institutos incluídos no estudo. Dessa maneira, também foi possível apontar o que existe em comum no processo de internacionalização dessas instituições.

\section{Mapeamento das políticas de PLE nas diferentes instituições}

\section{Colégio Pedro II}

O Colégio Pedro $\mathrm{II}^{6}$ é uma instituição de mais de 180 anos, sendo até hoje uma referência de ensino no estado. $O$ colégio oferece turmas da educação infantil, do ensino médio regular e integrado e de Pós-Graduação. A Assessoria Internacional do Colégio Pedro II (ARINTER) tem uma história recente na instituição e somente um professor era designado para este departamento no segundo semestre de 2018, que na hierarquia, prestava contas à vice-reitoria. Por isso, ele era o responsável pelo estabelecimento de parcerias, ingresso de estudantes intercambistas e pelo período que eles permaneceriam no colégio. No site institucional, ficava evidente que o colégio era bastante solicitado por instituições estrangeiras, que buscavam por acordos e cooperações com o centro educacional, o que reforçava a ideia da internacionalização como uma necessidade urgente e de inadiável implementação.

A instituição possuía três convênios direcionados para a recepção e saída de estudantes do Ensino Médio no momento da coleta dos dados, e mencionava registro de alunos de várias nacionalidades em mobilidade estudantil desde 2015.

De acordo com os dados, muitos estudantes realizavam intercâmbio com aproveitamento de estudos, e isso significava que eles faziam trabalhos e provas, sendo avaliados pelo desempenho nessas atividades, assim como todos os alunos do colégio. Normalmente, os estudantes intercambistas permaneciam no colégio durante um ano, e eram encaminhados para a unidade do colégio que era mais próxima ao seu local de moradia durante o período de mobilidade.

Quanto às políticas de PLE, constatou-se que ainda não existiam iniciativas voltadas para o ensino da língua. Talvez essa lacuna pudesse ser explicada pela carência de programa de mobilidades de recepção aos professores estrangeiros visitantes. Em

${ }^{6}$ O Colégio Pedro II foi incorporado à estrutura dos Institutos Federais por meio da Lei no 12.677, de 25 de junho de 2012. 
relação aos estudantes, identificaram-se registros que eles possuíam conhecimento quase nulo da língua portuguesa, mesmo aqueles que vinham em caráter de aproveitamento de estudos. Os estudantes encaminhados por uma Organização Internacional citada no respectivo site tinham acesso a uma plataforma digital de ensino de português, mas o estudo dependia somente da vontade do próprio aluno. No segundo semestre de 2018, nenhum aluno recebia acompanhamento quanto ao aprendizado do idioma por parte do Colégio Pedro II. Portanto, o português que os estudantes viriam a adquirir seria justamente mediante experiências compartilhadas no contexto escolar.

IFF

O IFF foi inaugurado em 1909, na cidade de Campos dos Goytacazes, e nesse período, a Escola de Aprendizes e Artífices, seria a nona a ser criada no Brasil. Na década de 1990, passou a ser um Centro Federal de Educação Tecnológica. Posteriormente, no ano de 2004, começar a oferecer também cursos superiores. Somente em 2008 foi denominado como Instituto Federal Fluminense.

O IFF possui 12 campi, incluindo municípios do Noroeste, do Norte, das Baixadas Litorâneas e da região Metropolitana do estado Rio de Janeiro. $O$ instituto oferece cursos técnicos (a maioria integrados ao Ensino Médio), licenciaturas, cursos superiores de tecnologia, bacharelados e também pós-graduação.

No site oficial do IFF, encontraram-se informações sobre o Escritório de Cooperação Internacional (ESCAI) e o nome da coordenação a cargo de uma professora de língua inglesa à época. De acordo com a página, o Escritório tinha por objetivo promover a interação do instituto com instituições no exterior, além de incentivar o intercâmbio docente e discente, para uma formação acadêmica mais completa. O ESCAI também estabelecia estratégias para dar maior visibilidade às ações de natureza técnicocientífica do Instituto no exterior, por meio da interação com instituições de ensino e pesquisa estrangeiras.

No segundo semestre de 2018, o IFF mantinha acordos com seis instituições estrangeiras. 0 campus Cabo Frio foi aquele que recebeu seus primeiros estudantes estrangeiros em 2014. A média por ano, aproximada, era de dois intercambistas ao ano, sendo o período de permanência na instituição em torno de dois ou três meses.

No que diz respeito às políticas linguísticas, a página do ESCAI reconhecia que os 
professores de línguas da instituição já eram peças fundamentais na proposição desse tipo de ação voltada para a internacionalização. A política dos Institutos Federais é justamente desenhar ações em âmbito local e agenciar programas que promovam transformações sociais. Como uma alternativa, a instituição estava implantando um curso de Português como Língua Adicional por meio da plataforma de educação à distância, demonstrando que tais ações de ensino poderão consolidar as parcerias internacionais nos próximos anos.

\section{CEFET/RJ}

O CEFET/RJ foi inaugurado em 1917, originalmente como a Escola Normal de Artes e Ofícios Wenceslau Braz. Atualmente, é uma das instituições tecnológicas mais conceituadas do Rio de Janeiro e possui oito campi, oferecendo ensino médio-técnico integrado, além de cursos de nível superior, graduação e pós-graduação.

Em 2005, o setor denominado Divisão de Cooperação Científico-Tecnológica, antes subordinado à Diretoria de Extensão, foi transferido para a Direção-Geral. A partir de outubro de 2015, por meio de uma portaria interna, passou a denominar-se Assessoria de Convênios e Relações Internacionais (ASCRI), como é conhecida ainda hoje.

Basicamente, a ASCRI é a responsável por coordenar as atividades de cooperação internacional no âmbito do sistema CEFET/RJ, assim como atuar identificando as demandas voltadas à internacionalização em níveis de ensino, pesquisa e extensão, além de buscar a ampliação contínua de intercâmbio ao público acadêmico. Dentre suas responsabilidades mais específicas, está o auxílio aos estudantes internacionais em suas necessidades de adaptação no Brasil e o apoio a aulas de português para aqueles que chegam à instituição por meio de acordos de cooperação assinados pela instituição.

A referida Assessoria, dentre as pesquisadas, é aquela com maior antiguidade e a que mais tempo desenvolve políticas de acolhimento e de ensino de PLE. No momento da coleta dos dados, o CEFET/RJ possuía trinta e quatro convênios internacionais e também era uma das únicas instituições tecnológicas a participar do Programa de Estudantes-Convênio de Graduação (PEC-G), que é administrado pelo Ministério das Relações Exteriores. O Ministério oferece a oportunidade de estudantes de vinte e seis países da África, vinte e cinco países da América Latina e Caribe, e nove países da Ásia de realizar seus estudos de graduação em instituições de Ensino Superior brasileiras. 
De acordo com as informações encontradas na página do CEFET/RJ, o número de intercambistas aumentou consideravelmente no ano de 2005, coincidentemente 0 ano em que a Assessoria recebeu a sua atual denominação e passou a funcionar subordinada à Direção-Geral. Por outro lado, o primeiro intercambista vindo pelo programa PEC-G chegou à instituição muito antes, no ano de 1994, segundo registros mantidos no site.

Com relação às políticas de ensino de PLE, a ASCRI registra iniciativas do próprio setor em parceria com professores. A demanda por aulas de português se iniciou com a vinda de estudantes americanos. Como a maioria dos alunos do PEC-G precisavam ser aprovados no exame oficial de proficiência Celpe-Bras e já chegavam ao Brasil sabendo português, algumas ações de PLE também foram desenvolvidas considerando esse público que precisava exercitar o idioma e conhecer aspectos e comportamentos culturais da cidade do Rio de Janeiro. Funcionou durante alguns anos na instituição o iClub, uma espécie de clube internacional, que contava com o apoio de estudantes de diferentes níveis de ensino e oferecia apoio aos intercambistas dos países com os quais o CEFET/RJ mantinha convênio de cooperação internacional.

Conforme registros, os estudantes americanos chegavam sem nenhuma noção do português. Foi nesse momento que surgiu a necessidade de se preparar aulas do idioma para que os intercambistas pudessem aprender, pelo menos, o básico para o seu cotidiano na instituição e na rotina da cidade. Além da própria assessora da época, temse o registro de outros professores de língua inglesa que auxiliaram na elaboração de aulas de português, inclusive da proposição da ementa e da oferta da disciplina de PLE nos cursos de ensino superior da instituição.

O protagonismo da instituição em ações de recepção e envio de estudantes demonstra como a internacionalização foi um processo desenhado e planejado para envolver também atividades de ensino, pesquisa, extensão. A seguir, relata-se uma ação extensionista na área de PLE vinculada ao ensino e à pesquisa.

\section{Projeto de PLE no CEFET/RJ: relato de uma experiência extensionista}

O projeto de extensão "Oficinas de ensino de Português para estrangeiros", cadastrado no Departamento de Extensão e Assuntos Comunitários, foi idealizado e coordenado por um docente de língua espanhola do Bacharelado LEANI desde sua implementação em 2017. O programa vinculou-se como atividade complementar da 
disciplina de graduação intitulada "Ensino intercultural de línguas estrangeiras", ministrada como componente optativo do referido Bacharelado.

O projeto foi desenhado para ofertar encontros de ensino de língua portuguesa e cultura, em particular da variedade brasileira, para estudantes estrangeiros do CEFET/RJ, professores visitantes, refugiados, turistas e residentes estrangeiros que tivessem como interesse desenvolver conhecimentos das destrezas linguísticas do português. Como objetivos para os bolsistas participantes, o projeto formativo propôs: promover reflexões sobre a área de ensino de PLE; refletir sobre práticas interculturais de ensino; exercitar saberes teóricos e práticos advindos do campo profissional da área de Linguagens; elaborar oficinas e materiais didáticos autênticos para o ensino de PLE; aprofundar conhecimentos teóricos sobre interculturalidade e ensino de línguas para fins específicos e proporcionar um estudo das narrativas de aprendizagem dos participantes das oficinas.

$\mathrm{Na}$ fase inicial de desenvolvimento do projeto, contava-se com um bolsista e duas voluntárias. Antes de iniciar as atividades práticas, foi preciso uma etapa de construção de uma bagagem teórico-metodológica sobre PLE e de como essa área vinha se desenvolvendo. Dessa forma, foi possível fomentar um pensamento crítico a respeito do tema e refletir qual seria a abordagem (ALMEIDA FILHO, 2017) mais eficiente para 0 desenho proposto para as oficinas da instituição.

Após o período de aproximação entre os atores do projeto e uma epistemologia da área de PLE, as primeiras ações começaram a ser desenhadas, com o propósito de implementar o projeto de ensino de PLE, uma vez que seria necessário divulgação para o público alvo, estabelecimento de local onde os encontros pudessem ocorrer, além da elaboração do material e do conteúdo que seria apresentado aos alunos estrangeiros. Com o objetivo de mapear o interesse, a disponibilidade e os temas de preferência dos intercambistas cefetianos, foi enviado um questionário com perguntas previamente elaboradas para cada um dos estudantes em mobilidade estudantil na época. Dessa forma, foi possível esclarecer os principais questionamentos sobre como proceder com o conteúdo e o tipo de material produzido para as oficinas a partir da análise de necessidades (RAMOS, 2019).

As primeiras oficinas foram colocadas em prática com três participantes francesas, que se encontravam em mobilidade no campus Maracanã e matriculadas no Bacharelado LEANI. Foram realizadas três oficinas antes da partida das alunas de volta ao seu país, possibilitando um primeiro piloto de como esse projeto era visto por alunos estrangeiros. 
Durante o segundo semestre de 2018, a maior dificuldade encontrada foi a disponibilidade dos intercambistas, já que estavam matriculados em cursos diversificados, portanto com horários diferenciados também. Além da questão de conseguir um horário e dia que atendesse a todos os alunos, eles também utilizavam a maior parte do seu tempo livre dedicando-se ao estudo das matérias que estavam cursando, porque se preocupavam com seus rendimentos nas disciplinas. Diante da possibilidade de não conseguir obter um grupo que tivesse uma presença contínua nas oficinas, a solução encontrada foi ofertar o ensino de PLE também para estrangeiros de fora da instituição.

O grupo que permaneceu presente durante o segundo semestre de oferecimento das oficinas de PLE constitua-se de três chinesas, que não eram alunas do CEFET/RJ, um peruano e um beninense, ambos estudantes intercambistas da instituição. Foram realizadas oficinas durante cinco meses. Os encontros priorizavam oferecer 0 conhecimento prático da língua, como a gramática, que era um pedido constante dos participantes, porém sempre dentro de uma contextualização da realidade social do país onde eles estavam vivendo no momento, buscando discutir sobre suas atividades cotidianas e refletindo sobre questões culturais.

Tanto com o grupo inicial de francesas quanto com o grupo misto, houve propostas de produção de textos e entrevistas para documentar suas opiniões e narrativas com o objetivo de saber se o projeto havia atendido ao seu público e também as etapas iniciais de planejamento dos bolsistas.

Em um dos textos escritos por uma das participantes francesas, ela comentava que gostou de aprender algumas expressões e que gostaria de se dedicar mais ao aprendizado da gramática, já que era um dos elementos que ela mais tinha dificuldades. Já uma segunda participante relatou que o projeto era uma ideia produtiva para os intercambistas que ainda virão, e acrescentou uma sugestão para que se organizem eventos para apresentar a cidade do Rio de Janeiro, de modo a possibilitar maior interação entre alunos estrangeiros e brasileiros.

Em uma das aulas realizadas com os participantes do grupo misto, foram feitas várias perguntas relacionadas à estrutura do projeto, sobre o conteúdo das oficinas e sobre possíveis sugestões, já que o projeto era realizado e planejado em função do seu público alvo, estudantes e cidadãos estrangeiros que residiam no Rio de Janeiro. Alguns deles destacaram que os cursos particulares de português possuíam preços elevados, e 
o projeto foi uma oportunidade de aprenderem a língua de forma gratuita. Dentre as participantes chinesas, a satisfação com a oportunidade de participar de um projeto gratuito de ensino de PLE foi unânime. Além disso, as participantes solicitaram um tipo de material fixo e contínuo para o semestre inteiro, como uma apostila ou somente um livro que servisse para todas as oficinas, pois o material era feito semana a semana, tentando abranger todas as solicitações e necessidades do grupo.

Algumas dificuldades iniciais voltaram a ser detectadas na reta final do projeto como, por exemplo, a disponibilidade dos participantes. Ao final do período de oferta das oficinais, foi dada aos participantes a possibilidade de aumentar a carga horária, realizando duas vezes na semana ou por mais tempo em um mesmo dia, porém, por mais que houvesse uma resposta positiva do público atendido, o horário e o dia de preferência de cada um eram divergentes. $O$ interesse quanto ao conteúdo também se demonstrou um pouco divergente. A vontade de treinar mais a escuta e a leitura ficou clara, apesar das sugestões de temas serem diversas, como história do Brasil, notícias do cotidiano e, ainda, culinária brasileira.

O participante peruano, e também aluno da graduação no CEFET/RJ, relatou que havia feito um curso de língua portuguesa antes de vir estudar no Brasil, mas que, para ele, seria importante aprender mais. Ele ainda ressaltou que tinha interesse em aprender a se apresentar, ou seja, melhorar a fala, e disse que gostaria que a instituição oferecesse um acompanhamento para o aprendizado de português de forma gradativa.

Conforme sinalizado, no decorrer das oficinas, atividades de produção escrita e entrevistas orais em português foram realizadas e o material apresentou muitos encaminhamentos para redesenhar as ações do projeto. Com isso, foi possível observar que, por mais que existam dificuldades e persistam algumas dúvidas quanto à língua, todos foram capazes de compreender as questões trabalhadas, as orientações fornecidas e a se expressar acerca do projeto e de como ele os aproximou da língua, fomentando também a vontade de continuar estudando o idioma.

\section{Considerações finais}

O ano de 2008 foi o marco da educação profissional e tecnológica no Brasil com a criação dos Institutos Federais de Educação, Ciência e Tecnologia e de um novo desenho da educação tecnológica no país, o que ocasionou mudanças significativas no contexto educacional e trouxe a expansão da rede federal. A internacionalização do ensino superior 
se deu, inicialmente pelo Programa Ciência sem Fronteiras, no sentido de promover também a consolidação e a expansão internacional da ciência e tecnologia (FERRARI, 2015, p. 1004), no entanto, outras ações precisam ser vislumbradas pelas instituições de ensino para o agenciamento da internacionalização.

Nos últimos anos, essas instituições buscam estabelecer suas ações e modelos de internacionalização, cada uma de acordo com suas possibilidades e graus de desenvolvimento. Com isso, fica claro que a cooperação internacional é de suma importância para institutos e universidades, instituições produtoras de conhecimento, porém ainda é preciso acompanhar esse processo (MOROSINI, 2011, p. 109).

Voltando-se especificamente para o caso das instituições destacadas neste artigo, por mais que todas participem de ações e redes de incentivo à cooperação acadêmica internacional, como a Rede de Assessorias Internacionais das Instituições de Ensino Superior do Rio de Janeiro (REARI-RJ), todas encaminham suas ações de forma distinta e também apresentam níveis internos diferentes quando se trata do processo de internacionalização. Talvez por isso que esse processo seja descrita como "conceito complexo, com uma diversidade de termos relacionados, apresentando diversas fases de desenvolvimento" (MOROSINI, 2006, p. 115).

Ressaltado em algumas páginas institucionais, o processo de internacionalização e a mobilidade estudantil têm se tornado pautas constantes no ensino superior, e devese reconhecer o seu papel social e cultural. O desenvolvimento humano por meio do intercâmbio de saberes e a ampliação da diversidade de conhecimentos contribuem para a renovação e trazem enriquecimento cultural para ambos os países, de acolhimento e de origem (FIGUEIREDO; OSÓRIO; MIRANDA, 2012).

É justamente devido ao fortalecimento da internacionalização das instituições brasileiras e das políticas de difusão do português no exterior que será cada vez mais importante pensar criticamente as bases da institucionalização da área de PLE (DINIZ, 2015). O autor orienta a pensar o ensino-aprendizagem da língua não como potencial econômico, mas sim como uma "língua de saber".

As políticas linguísticas ainda não se constituem totalmente como o foco da internacionalização das instituições analisadas. Muitas podem ser as causas para a ausência de ações voltadas para este fim em algumas delas: processo de instalação e transição nos departamentos responsáveis pela cooperação e mobilidade estudantil, 
carência de conhecimento sobre a pauta da internacionalização, falta de adesão e apoio interno ao processo de internacionalização, baixo número de estudantes intercambistas em mobilidade, entre outras.

Naquelas instituições onde políticas de ensino de PLE já foram ou estão sendo desenvolvidas, como se ilustrou com o caso do CEFET/RJ, nota-se uma quantidade maior de convênios e parcerias internacionais e um maior número de intercambistas em mobilidade por ano. Nem todas estas políticas podem ser propostas diretamente pela diretoria ou assessoria de relações internacionais, mas elas influenciam na estrutura de recepção e adaptação dos estudantes estrangeiros que, por ventura, venham realizar um período de mobilidade. Essa é mais uma prova da importância do envolvimento da instituição como um todo para que o processo se torne, com o passar do tempo, cada vez mais natural no âmbito institucional.

Mas ao contrário do que se pode imaginar, nenhuma das instituições se mantém alheia às possibilidades de estabelecer cooperação, parcerias ou promover programas de pesquisa com instituições estrangeiras, e também das necessidades desses alunos em mobilidade internacional.

Por fim, este artigo possibilitou um levantamento inicial das ações e políticas de PLE das instituições pesquisadas a partir de informações divulgadas nos respectivos sites institucionais. O desenho proposto para o estudo não permitiu ouvir os funcionários, professores, estudantes e assessores internacionais para conhecer outras perspectivas e práticas no âmbito da internacionalização. Essa carência aponta para a necessidade de complementar o estudo e atualizar o debate por meio do uso de entrevistas e questionários nas realidades investigadas. Além disso, destacou-se, ainda, o projeto de extensão do CEFET/RJ como uma forma de apontar caminhos alternativos de difusão como PLE com a instalação do Bacharelado LEANI. Pretende-se ainda manter aberto o debate em publicações futuras quanto às estratégias de internacionalização e um olhar crítico sobre esse processo, bem como a importância das políticas de língua e a institucionalização da área acadêmica e profissional de PLE.

\section{Referências}

ABREU-e-LIMA, Denise Martins; SARMENTO, Simone; MORAES FILHO, Waldenor

Barros. O programa idiomas sem fronteiras. In: SARMENTO, Simone; ABREU-e-LIMA, Denise Martins; MORAES FILHO, Waldenor Barros (org.). Do Inglês sem Fronteiras ao Idiomas sem Fronteiras. a construção de uma política linguística para a 
internacionalização. Belo Horizonte: Editora UFMG, 2016. p. 293-308.

ALMEIDA FILHO, José Carlos Paes de. Ensino de Português Língua Estrangeira/EPLE: a emergência de uma área. In: ALMEIDA FILHO, José Carlos Paes de (org.).

Fundamentos de abordagem e formação no ensino de PLE e de outras línguas. 2. ed. Campinas: Pontes Editores, 2017. p. 93-104.

ALTBACH, Philip G.; KNIGHT, Jane. The internationalization of higher education: motivations and realities. Journal of Studies in International Education, [s. I.], v. 11, n. 3/4, p. 290-305, 2007.

BIZON, Ana Cecília Cossi. Narrando o exame Celpe-Bras e o convênio PEC-G: a construção de territorialidades em tempos de internacionalização. 2013. Tese (Doutorado) - Instituto de Estudos da Linguagem, Universidade Estadual de Campinas, 2013.

BRASIL. Lei No 11.892, de 29 de dezembro de 2008. Institui a Rede Federal de Educação Profissional, Científica e Tecnológica, cria os Institutos Federais de Educação, Ciência e Tecnologia, e dá outras providências. Diário Oficial da União, Brasília, DF, 29 dez. 2008. Disponível em: http://www.planalto.gov.br/ccivil 03/ ato20072010/2008/lei/l11892.htm. Acesso em: 9 out. 2021.

CHAGAS, Lucas Araújo. Entre experiências e indícios: o ensino de português para estrangeiros em contexto de imersão linguística. 2016. Dissertação (Mestrado em Estudos Linguísticos) - Universidade Federal de Uberlândia, Uberlândia, 2016.

DINIZ, Leandro Rodrigues Alves. Entre discursos mercadológicos e nacionalistas: apontamentos para o ensino-aprendizagem de português para falantes de outras línguas. Entremeios: Revista de Estudos do Discurso, [Belo Horizonte], v. 10, p. 5-8, jan./jun. 2015.

DINIZ, Leandro Rodrigues Alves. Mercado de linguas. a instrumentalização brasileira do português como língua estrangeira. 2008. Dissertação (Mestrado) - Instituto de Estudos da Linguagem, Universidade Estadual de Campinas, Campinas, 2008.

DINIZ, Leandro Rodrigues Alves. Política linguística do estado brasileiro na contemporaneidade: a institucionalização de mecanismos de promoção da língua nacional no exterior. 2012. Tese (Doutorado) - Instituto de Estudos da Linguagem, Universidade Estadual de Campinas, Campinas, 2012.

FERRARI, Mari. A internacionalização dos institutos federais: um estudo sobre o acordo Brasil-Canadá. Educação \& Sociedade, Campinas, v. 36, n. 133, p. 1003-1019, out./dez. 2015.

FIGUEIREDO, F. J. Q.; OSÓRIO, P.; MIRANDA, F. Contribuições da linguística aplicada para o ensino e aprendizagem de português como língua estrangeira. In: ROMERO, Tania R. S.; FERREIRA, Maria Cristina Faria Dalacorte; REICHMANN, Carla Lynn. (org.). Construções identitárias de professores de línguas. Campinas: Pontes, 2012. p. 103116. 
KNIGHT, Jane. International universities: misunderstandings and emerging models? Journal of Studies in International Education, [s. I.], v. 19, n. 2, p. 1-15, 2015.

KNIGHT, Jane. Internationalization remodeled: definition, approaches, and rationales. Journal of Studies in International Education, [s. I.], v. 8, n. 1, p. 5-31, 2004.

LIMA, Manolita Correia; MARANHÃO, Carolina Machado Saraiva de Albuquerque. O sistema de educação superior mundial: entre a internacionalização ativa e passiva. Avaliação, Sorocaba, v. 14, n. 3, p. 583-610, nov. 2009.

MOROSINI, Marília Costa. Internacionalização da educação superior - Conceitos e práticas. Educar, Curitiba, n. 28, p. 107-124, 2006.

MOROSINI, Marília Costa. Internacionalização na produção de conhecimento em IES brasileiras: cooperação internacional tradicional e cooperação internacional horizontal. Educação em Revista, Belo Horizonte, v. 27, n. 1, p. 93-112, abr. 2011.

MOUTINHO, Ricardo; ALMEIDA FILHO, José Carlos Paes de. Aprender PLE na Universidade. In: ALMEIDA FILHO, José Carlos Paes de. (org.). Fundamentos de abordagem e formação no ensino de PLE e de outras línguas. 2. ed. Campinas: Pontes Editores, 2017. p. 65-79.

NORTE, A. L.; SILVA JÚNIOR, A. F. Uma experiência de internacionalização no Cefet/Rj: a criação do Bacharelado em Línguas Estrangeiras Aplicadas às Negociações Internacionais. In: COELHO, Iandra Maria Weirich da Silva (org.). A Internacionalização da Rede Federal de Educação Profissional, Científica e Tecnológica: fundamentos, ações e perspectivas. Campinas: Pontes Editores, 2018. v. 1, p. 99-113.

RAMOS, Rosinda de Castro Guerra. De instrumental a LinFE: percursos e equívocos da área no Brasil. In: SILVA JÚNIOR, Antonio Ferreira da (org.). Línguas para fins específicos: revisitando conceitos e práticas. Campinas: Pontes Editores, 2019. p. 2341.

SENHORAS, Eloi Martins. O papel da internacionalização das universidades e a projeção da cooperação internacional do Mercosul. In: SEMINÁRIO INTERNACIONAL CIÊNCIA E TECNOLOGIA NA AMÉRICA LATINA, 3., 2006, Campinas. Anais [...]. Campinas: Unicamp, 2006.

TEICHLER, Ulrich. The changing debate on internationalisation of higher education. Higher Education, Washington, v. 48, n. 1, p. 5-26, 2004. 